\title{
Depressed Mood and the Incidence of Alzheimer's Disease in the Elderly Living in the Community
}

\author{
D. P. Devanand, MD; Mary Sano, PhD; Ming-Xin Tang, PhD; Stuart Taylor, MD; \\ Barry J. Gurland, MD; David Wilder, PhD; Yaakov Stern, PhD; Richard Mayeux, MD
}

\begin{abstract}
Background: It remains unclear whether depression increases the risk for dementia in the elderly. We evaluated the relationship between depressed mood at baseline and the incidence of dementia, particularly Alzheimer's disease, in the elderly living in the community.
\end{abstract}

\begin{abstract}
Methods: A total of 1070 elderly individuals, aged 60 years or older, were identified as part of a registry for dementia in the Washington Heights community of North Manhattan, NY. In a prospective, longitudinal design with follow-up for 1 to 5 years, annual physician evaluation and neuropsychological testing were used to assess levels of cognitive impairment and to diagnose dementia. Depressive symptoms were evaluated with the 17-item Hamilton Rating Scale for Depression. Based on clinical considerations and a validity study, a positive score for the depressed mood item was used in statistical analyses. To confirm the results, the total Hamilton Rating Scale for Depression score was also evaluated as the "depression" variable.
\end{abstract}

Results: Of the 1070 subjects, 218 met criteria for dementia at baseline evaluation. In the 852 subjects without dementia, depressed mood was more common in individuals with greater cognitive impairment. In a follow-up study of 478 of these subjects without demen- tia (mean $\pm S D, 2.54 \pm 1.12$ years of follow-up), the effect of baseline depressed mood on the end-point diagnosis of dementia (93\% had possible or probable Alzheimer's disease) was evaluated in a Cox proportional hazards model. Depressed mood at baseline was associated with an increased risk of incident dementia (relative risk, 2.94; 95\% confidence interval, 1.76 to 4.91 ; $P<.001)$. This effect remained after adjustment for age, gender, education, language of assessment, Blessed Memory Information and Concentration test scores, and Blessed Functional Activity Scale scores (relative risk, 2.05; $95 \%$ confidence interval, 1.16 to $3.62 ; P<.02$ ). Similar results were obtained when the total Hamilton Rating Scale for Depression score was used as the depression variable, with the use of the same covariates (relative risk, 1.07 per point interval; $95 \%$ confidence interval, 1.02 to $1.11 ; P<.01)$.

Conclusions: Depressed mood moderately increased the risk of developing dementia, primarily Alzheimer's disease. Whether depressed mood is a very early manifestation of Alzheimer's disease, or increases susceptibility through another mechanism, remains to be determined.

(Arch Gen Psychiatry. 1996;53:175-182)
From the Gertrude $\mathrm{H}$. Sergievsky Center and the Center for Alzheimer's Disease Research in New York City (Drs Devanand, Sano, Tang, Taylor, Gurland, Wilder, Stern, and Mayeux), the Center for Geriatrics at Columbia University (Drs Gurland and Wilder), the Department of Biological Psychiatry, New York State Psychiatric Institute (Drs Devanand, Stern, and Mayeux), and the Departments of Psychiatry (Drs Devanand, Taylor, Gurland, and Wilder) and Neurology (Drs Sano, Tang, Stern, and Mayeux), College of Physicians and Surgeons of Columbia University, New York, NY.

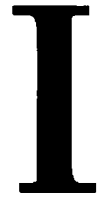

$\mathrm{N}$ THE ELDERLY, it remains unclear whether depression increases the risk of dementia. Depression may be associated with cognitive deficits, and some patients with dementia manifest depressive symptoms. ${ }^{1-6}$ Approximately $10 \%$ to $30 \%$ of patients with Alzheimer's disease (AD) meet criteria for major depression. ${ }^{7-10} \mathrm{How}-$ ever, some symptoms used to diagnose depressive disorders, including psychomotor change, apathy or lack of interest, sleep difficulties, and disturbances in thinking or concentration, frequently occur in demented patients who are not depressed. ${ }^{11-13}$ These nonspecific symptoms may artificially raise the reported prevalence of depression in demented patients.

In the clinically depressed elderly, mild cognitive impairment is not uncommon. ${ }^{14,15}$ This cognitive dysfunction improves to varying degrees once the depressive symptoms subside ${ }^{16,17}$ However, there is growing evidence that some of these clinically depressed patients with cognitive impairment develop irreversible dementia in 2 or more years, ${ }^{16,18,19}$ although there are some dissenting reports. ${ }^{20,21}$ In clinical samples, follow-up studies indicate that cognitively intact elderly patients with depression have only a slightly higher probability of developing dementia than the general population. ${ }^{22,23}$

See Subjects and Methods on next page 


\section{SUBJECTS AND METHODS}

\section{SUBJECTS}

All subjects provided written informed consent to participate in the Washington Heights-Inwood and Columbia Aging Project, a prospective investigation of AD and dementias associated with Parkinson's disease and stroke. Informed consent was obtained from subjects and appropriate advocates, as defined by the Columbia University ( $\mathrm{New}$ York, NY) institutional review board that approved this project. Sources of potential subjects included referrals by community-based health care providers, random samples from a commercial list and a list obtained from the Health Care Financing Agency, a state agency list of home care recipients, self-referred volunteers, and solicitation by news media. Other details of subject recruitment to this community registry have been described elsewhere. ${ }^{34,35}$ Recruitment was limited to a geographically defined area of northern Manhattan.

The present study sample was selected by excluding all subjects identified by a physician to have stroke (by history or by focal neurologic signs or by radiologic evidence consistent with stroke), Parkinson's disease, Huntington's disease, multiple sclerosis, brain tumor, schizophrenia, or mental retardation. Major depression was not an exclusion criterion. Subjects were examined at their residence (home or nursing home), senior citizen center, other community facility, or in a research clinic. Follow-up was conducted with an identical set of evaluation procedures at 1 -year intervals for a maximum of 5 years.

\section{DIAGNOSTIC EVALUATION}

All evaluations were conducted in either English or Spanish, based on the subjects' primary language and their opinion of which language would yield better performance. A physician obtained a semistructured medical history, conducted a physical and neurologic examination, completed the modified short Blessed Memory Information and Concentration test (BMIC) ${ }^{36}$ reviewed the Blessed Functional Activity Scale (BFAS parts 1 and 2), ${ }^{34.36}$ and completed the Clinical Dementia Rating. ${ }^{37}$ Prescribed medications were reviewed and recorded. The physician, usually a neurolo- gist or internist, also obtained a history of psychotropic medication use and electroconvulsive therapy and made the diagnosis of major depression based on clinical impression. The physician used DSM-III-R criteria ${ }^{38}$ as a guideline, but there was no attempt to establish reliability of the physician's diagnosis of major depression.

A research technician administered a standardized neuropsychological test battery that assessed memory (verbal and nonverbal), orientation, abstract reasoning, language, and visuospatial abilities. These procedures have been described elsewhere. ${ }^{34}$

The initial diagnosis of dementia was based on a fixed paradigm that used a priori cutoff scores on the neuropsychological tests and evidence of impairment in social or occupational function. ${ }^{34,35}$ These cutoff scores on neuropsychological tests were established after the cognitive effects of depression, stroke, and Parkinson's disease were taken into account. ${ }^{34}$ As a result, the cutoff scores were conservative enough to avoid misclassification of these three conditions as dementia. The final diagnosis was based on a consensus conference between physicians and neuropsychologists. The diagnosis of dementia was based on the DSM-III-R criteria and required evidence of memory impairment and other cognitive deficits based on a neuropsychological test paradigm, as well as evidence of impairment in social or occupational function based on the formal functional assessment, elicited history, or both. After this final consensus diagnosis, subjects who were rated as demented were classified according to cause, based on the available medical and neurologic information. The criteria of the National Institute of Neurological and Communicative Disorders and StrokeAlzheimer's Disease and Related Disorders Association ${ }^{39}$ were used to make the diagnosis of possible or probable AD. In this consensus diagnostic conference, there was no attempt to classify depressive diagnoses according to DSM-III-R.

Nondemented subjects were classified into one of three categories: (1) no cognitive impairment (no more than one neuropsychological test score below cutoffs, no functional impairment, and Clinical Dementia Rating of 0 ); (2) mild cognitive impairment (two or more test scores below cutoffs, no functional impairment, and Clinical Dementia Rating of 0 ); and (3) moderate cognitive impairment (two or more test scores below cutoffs, no functional impairment, and Clinical Dementia Rating of 0.5).

Follow-up evaluations were conducted at annual in-
Few epidemiologic studies have directly assessed depression as a risk factor for dementia, and many have excluded depressed individuals during sample selection. ${ }^{24}$ These studies, mostly of the case-control type, suggest that a history of medically treated depression is more common in cases of dementia than in controls, ${ }^{25-31}$ with limited contrary evidence..$^{32}$ Overall, these studies suggest that a history of depression slightly increases the risk of dementia. ${ }^{24}$

Major limitations of many of these epidemiologic studies include the use of a case-control design, reliance on history of depression obtained primarily from medical records and informant interviews, absence of direct evaluation of depression, and low statistical power. ${ }^{33}$ To our knowledge, there are no published longitudinal epidemiologic studies that have used systematic assessments of depression and cognition to determine whether depression is a risk factor for dementia. In a prospective, longitudinal, population-based study that used direct clinical evaluation of elderly subjects identified from a community registry in a circumscribed geographic area, we evaluated the relationship between the presence of depression and the incidence of dementia, particularly AD.

\section{RESULTS}

\section{BASELINE SAMPLE}

Baseline information was collected for 1070 subjects. Their demographic and clinical features are described in Table 1. The ethnic breakdown was $30 \%$ non-Latino white, $41 \%$ Latino, and 27\% African American, with $1 \%$ in other categories. For some clinical variables, eg, psy- 
tervals, with the use of the same diagnostic consensus conference procedures. Follow-up diagnoses were made without knowledge of any baseline information. At the diagnostic consensus conference, staff were aware of whether the subject was depressed at that time. However, this did not influence the diagnosis of dementia because the primary dementia criterion, cognitive deficit, was based on a fixed neuropsychological test score paradigm. In addition, subjects were studied as part of a larger study with goals unrelated to those of this report.

\section{DEPRESSION}

Two senior researchers formally trained and supervised the interviewers in the use of the HRSD, with the aid of didactic sessions, videotapes, and in-person interviews. The trained interviewer used a semistructured interview guide to administer the 17-item HRSD to the patient. ${ }^{40}$ In demented subjects, additional information was obtained from an informant.

To establish reliability, in a series of 52 elderly subjects ( 32 patients with stroke and 20 normal controls; mean age, 71.5 years), three trained raters and one clinical psychologist conducted interviews in pairs in which one rater administered the scale and the other rater observed the interview. Both raters made independent ratings. Intraclass correlation coefficients were .86 for the depressed mood item and .96 for the total HRSD score.

In a separate validity study of 36 elderly subjects ( 13 patients with Parkinson's disease and 23 normal controls; mean age, 73.4 years), a trained interviewer administered the HRSD and a psychiatrist (S.T.) independently conducted the Structured Clinical Interview for DSM-III- $R^{38}$ to diagnose major depressive disorder. In these 36 subjects, the mean $( \pm S D)$ HRSD score was $4.4 \pm 2.8$. Six $(17 \%)$ of these 36 subjects met criteria for major depressive disorder. For the single HRSD item of depressed mood relative to the Structured Clinical Interview for DSM-III-R diagnosis of major depressive disorder, sensitivity was $83 \%$ and specificity was $70 \%$. Sensitivity and specificity were not improved further by the inclusion of any other HRSD item, or by the total HRSD score (dichotomized as $\geq 10$ or $<10$ ).

The symptoms of lack of interest, agitation, insomnia, and weight loss are not uncommon in $\mathrm{AD}$, and the diagnosis of major depression and the total HRSD score can be misleading in such cases. Given these considerations, and the results of the validity study, the HRSD depressed mood item alone (dichotomized as present or absent) was the main variable used for "depression" in statistical analyses. To confirm the results obtained with the depressed mood item, the total HRSD score was also evaluated as the depression variable.

Recent evidence ${ }^{41,42}$ suggests a strong association between the presence of the apolipoprotein E- $\epsilon 4$ allele and AD. During the last year of the study, blood was drawn from a subset of available subjects who consented to assessment of the apolipoprotein E genotype.

\section{STATISTICAL ANALYSIS}

\section{Baseline Evaluation}

Analyses by $\chi^{2}$ or two-tailed Student's $t$ tests were conducted to compare the demographic and clinical features in subjects with and without dementia. Analyses of variance and $\chi^{2}$ analyses were used to compare relevant demographic and clinical variables in the three subgroups with no, mild, and moderate cognitive impairment. A logistic regression model was used to assess the independent effects of age, education, language, and depression on the diagnosis of dementia.

\section{Follow-up}

Cox proportional hazards models ${ }^{43}$ were used to assess the relative risk (RR) of incident dementia associated with depression. The timing variable was the duration from the initial visit to the first follow-up time point at which the diagnosis of dementia was made. Follow-up Cox analyses were recalculated with adjustment for age, gender, education, language of assessment (English or Spanish), BMIC scores (range, 0 to 28), and BFAS scores (range, 0 to 17).

In the sample subset in which apolipoprotein E genotypes were determined, subjects with the apolipoprotein E-€4 allele (homozygous or heterozygous) were classified into one group, and the remaining subjects formed the other group. The Cox proportional hazards model was used to determine if the association of depression with incident dementia remained after accounting for the effect of apolipoprotein $\mathrm{E}-\mathrm{\epsilon} 4$ on disease risk. chiatric history, information was not obtained, or could not be obtained reliably, in $1 \%$ to $7 \%$ of subjects. Compared with the 852 subjects rated as not demented, the 218 demented patients were older, had less education, and were more impaired on tests of cognition (BMIC) and functional ability (BFAS). Of the demented subjects, $89 \%$ were given a diagnosis of possible or probable AD with or without concomitant contributory conditions.

Compared with subjects without dementia, the subjects with dementia more frequently scored positively on the HRSD depressed mood item and had significantly higher HRSD total scores (Table 1). Patients with dementia were more likely to be prescribed anxiolytic medications. The two groups did not differ with respect to a history of psychiatric disorder or current or past treatment with antidepressant medications or electroconvul- sive therapy (Table 1). The specific type of past psychiatric disorder was not ascertained.

A logistic regression model was used to identify the independent effects of median age ( $\leq 74$ years vs $>74$ years), education ( $\leq 8$ years vs $>8$ years), language (English or Spanish), and depression on the diagnosis of dementia at baseline evaluation. Median age (RR, 6.22; $95 \%$ confidence interval [CI] 4.17 to $9.13 ; \mathrm{P}<.001$ ) and education (RR, $2.27 ; 95 \% \mathrm{CI}, 1.53$ to $3.36 ; P<.001$ ) were strongly associated, but depressed mood $(R R, 1.34 ; 95 \%$ $\mathrm{CI}, 0.96$ to $1.87 ; \mathrm{P}<.1$ ) and language $(\mathrm{RR}, 1.38 ; 95 \% \mathrm{CI}$, 0.93 to $2.04 ; P=.11$ ) were not associated with the diagnosis of dementia at baseline evaluation.

The degree of cognitive impairment was rated in 849 of the 852 subjects who were not demented at baseline evaluation. Of the 849 subjects, 452 (53\%) had no cognitive impairment, 243 (29\%) had mild cognitive im- 
pairment, and 112 (13\%) had moderate cognitive impairment. In these three subgroups, the demographic and clinical features were compared (Table 2). There were no differences in gender, history of psychiatric disorder, or current psychotropic medication usage. Greater cognitive impairment was associated with increased age, lower education, and Spanish as the language of assessment. The presence of major depression as determined by the physician's clinical impression, as well as positive scores for the depressed mood item and the total HRSD score, increased significantly with greater cognitive impairment.

In the 849 subjects without dementia, the subgroups with and without a positive score for the HRSD depressed mood item were compared on cognitive performance and functional ability. The depressed group performed more poorly on the BMIC (mean \pm SD, $4.9 \pm 4.4$ vs $4.0 \pm 4.2 ; t=2.9, P<.005$ ) and showed greater functional impairment on the BFAS $(2.7 \pm 3.3$ vs $1.5 \pm 2.6$; $t=6.8, P<.001)$.

\section{FOLLOW-UP SAMPLE}

Of the 849 subjects rated not demented at baseline evaluation, at least one follow-up evaluation was conducted in 478 subjects during a 1 - to 5 -year period (mean \pm SD follow-up, $2.54 \pm 1.12$ years). The number of subjects followed up at each time point was as follows: 391 at year 1,346 at year 2, 216 at year 3, and 105 at year 4 . Of the 353 subjects who were not followed up, 165 subjects were recruited in the last year of the study, which has ended. Reasons for failure to reexamine the others were death $(n=15)$, unavailability for follow-up or relocation $(n=125)$, and refusal $(n=48)$. There were no significant differences in gender, age, language, and depression scores between subjects who were and were not followed up. Duration of follow-up was greater in subjects with a high level of education compared with those with a low level of education $\left(\chi^{2}=9.2, P<.01\right)$. The mean $( \pm S D)$ number of years of education was $10.4 \pm 4.8$ for subjects who were followed up and $8.9 \pm 4.7$ for subjects who were not followed up.

The persistence of depressed mood over time was evaluated in the subjects who were followed up. One hundred seven $(62 \%)$ of the 173 subjects with depressed mood at baseline had depressed mood at 1-year follow-up, and $75 \%$ of the 283 subjects without depressed mood at baseline did not have depressed mood at 1-year follow-up $\left(\chi^{2}=62.1, P<.001\right)$. Similarly, $63 \%$ of subjects with depressed mood at baseline had depressed mood at 2-year follow-up, and $73 \%$ of subjects without depressed mood at baseline did not have depressed mood at 2-year follow-up $\left(\chi^{2}=42.8, P<.001\right)$. These findings suggested that depressed mood was often an enduring symptom and provided indirect evidence that the interviewers made consistent ratings during the study.

Of the 478 subjects who were followed up, 61 reached the end-point diagnosis of dementia. These 61 subjects comprised $36(21 \%)$ of 173 subjects who were depressed and 25 (9\%) of 283 subjects who were not depressed at baseline evaluation $\left(\chi^{2}=13.3, P<.001\right)$. At baseline evaluation, these 36 depressed subjects had higher
Table 1. Baseline Demographic and Clinical Features of the Sample*

\begin{tabular}{lccc}
\hline Variable & Dementia & $\begin{array}{c}\text { No } \\
\text { Dementia }\end{array}$ & Pt \\
\hline Baseline sample, No. & 218 & 852 & $\ldots$. \\
Age, y (mean \pm SD) & $81.9 \pm 8.1$ & $73.4 \pm 7.3$ & $<.001$ \\
Gender, \% F & 78.4 & 69.4 & $<.01$ \\
Education, y (mean \pm SD) & $6.8 \pm 4.3$ & $9.7 \pm 4.8$ & $<.001$ \\
Language of assessment, \% & & & \\
$\quad$ English & 47.9 & 61.9 & $<.001$ \\
$\quad$ Spanish & 52.1 & 38.1 & $\ldots$. \\
BMIC (mean \pm SD) & $16.4 \pm 7.1$ & $4.3 \pm 4.3$ & $<.001$ \\
BFAS (mean \pm SD) & $5.3 \pm 4.2$ & $1.1 \pm 1.7$ & $<.001$ \\
Total HRSD score (mean \pm SD) & $6.1 \pm 5.6$ & $4.5 \pm 4.6$ & $<.001$ \\
HRSD depressed mood item, & & & \\
$\quad \%$ positive score & 49.1 & 37.4 & $<.01$ \\
Current antidepressant use, \% & 2.4 & 2.2 & .86 \\
Current anxiolytic use, \% & 8.5 & 3.1 & $<.001$ \\
History of psychiatric disorder, \% & 10.5 & 7.9 & .23 \\
Ever took antidepressants, \% & 4.0 & 6.8 & .16 \\
Ever received ECT, \% & 2.2 & 1.8 & .70 \\
\end{tabular}

* BMIC indicates Blessed Memory Information and Concentration Test (range, 0 to 28); BFAS, Blessed Functional Activity Scale (parts 1 and 2; range, 0 to 17); HRSD, Hamilton Rating Scale for Depression; and ECT, electroconvulsive therapy.

$\dagger A$ test of significance for $\chi^{2}$ (categorical variables) or two-tailed $\mathrm{t}$ test (continuous variables), as appropriate.

depression (HRSD) and functional impairment (BFAS) scores and were more likely to be Latino (Spanishspeaking) than the 25 nondepressed subjects who developed dementia on follow-up (Table 3). However, these two groups did not differ in age, gender, duration from the baseline visit to the final diagnosis of dementia, and BMIC scores. The mean $( \pm S D)$ HRSD score in the depressed group (9.0 \pm 6.1$)$ indicated that the depressive syndromes experienced by these subjects were often mild. On the HRSD depressed mood item (scored 0 [absent] to 4 [severely depressed]), 22 (61\%) of these $36 \mathrm{de}-$ pressed subjects received a score of 1,11 subjects $(31 \%)$ received a score of 2 , three subjects ( $8 \%$ ) received a score of 3 , and none received a score of 4 . The 36 depressed subjects who developed dementia on follow-up did not differ significantly in baseline total HRSD scores (mean \pm SD, 9.0 \pm 6.1 ) from the 137 depressed subjects $(7.5 \pm 4.9 ; t=1.56)$ who did not develop dementia on follow-up.

Fifty-seven (93\%) of these 61 incident dementia cases were classified as possible $(n=9)$ or probable $(n=48) A D$. Of the remaining four incident dementia cases, one had progressive supranuclear palsy. The other three incident dementia cases had a progressive clinical course consistent with AD but had other conditions (head injury, alcohol dependence with motor vehicle accident, and multiple sclerosis that developed after the initial evaluation) that were deemed contributing factors. Regardless of dementia subtype, data for all subjects were retained in the main analyses. A Cox proportional hazards model evaluated the effect of baseline depressed mood on the end-point diagnosis of dementia. The RR for reaching this end point was significantly greater in subjects with depressed mood at baseline (RR, 2.94; $95 \% \mathrm{CI}, 1.76$ to 4.91 ; $P<.001)$. The Figure presents the survival curves for 
Table 2. Baseline Features of Subgroups With No, Mild, and Moderate Cognitive Impairment*

\begin{tabular}{|c|c|c|c|c|}
\hline Variable & $\begin{array}{l}\text { No Cognitive } \\
\text { Impairment }\end{array}$ & Mild Impairment & Moderate impairment & $P t$ \\
\hline Total No. & 452 & 279 & 118 & \\
\hline Gender, \% F & 70.1 & 66.7 & 73.7 & .34 \\
\hline Age, y $($ mean $\pm S D)$ & $71.6 \pm 6.6$ & $74.5 \pm 7.5$ & $77.7 \pm 7.8$ & $<.001$ \\
\hline Education, y (mean $\pm S D)$ & $11.8 \pm 4.2$ & $7.8 \pm 4.3$ & $6.7 \pm 4.2$ & $<.001$ \\
\hline Language, \% Spanish & 25.7 & 48.6 & 50.8 & $<.001$ \\
\hline BMIC (mean $\pm S D)$ & $2.5 \pm 2.8$ & $5.5 \pm 4.1$ & $8.6 \pm 5.2$ & $<.001$ \\
\hline $\mathrm{BFAS}($ mean $\pm S D)$ & $0.7 \pm 1.3$ & $1.3 \pm 1.5$ & $2.4 \pm 2.4$ & $<.001$ \\
\hline Past psychiatric disorder, \% & 8.5 & 6.9 & 8.5 & .72 \\
\hline Current antidepressant use, $\%$ & 1.4 & 3.3 & 2.6 & .21 \\
\hline Current anxiolytic use, $\%$ & 2.5 & 4.5 & 2.6 & .33 \\
\hline Ever took antidepressants, \% & 8.7 & 3.6 & 6.0 & .06 \\
\hline Ever received ECT, \% & 2.4 & 1.0 & 1.2 & .46 \\
\hline Major depression, current \% $\ddagger$ & 1.5 & 2.9 & 6.8 & $<.01$ \\
\hline Total HRSD score (mean \pm SD) & $3.8 \pm 3.9$ & $4.9 \pm 4.6$ & $6.6 \pm 6.3$ & $<.001$ \\
\hline Depressed mood, \% & 30.3 & 42.9 & 52.5 & $<.001$ \\
\hline
\end{tabular}

*BMIC indicates Blessed Memory Information and Concentration Test; BFAS, Blessed Functional Activity Scale (parts 1 and 2); ECT, electroconvulsive therapy; and HRSD. Hamilton Rating Scale for Depression.

$\dagger$ Level of significance in analysis of variance or $\chi^{2}$, as appropriate.

$\ddagger$ Diagnosis of major depression was based on the clinical impression of the physician, usually a neurologist or internist.

Table 3. Comparison of Depressed and

Nondepressed Subjects With Incident Dementia*

\begin{tabular}{|c|c|c|c|}
\hline Variable & Depressed & $\begin{array}{c}\text { Not } \\
\text { Depressed }\end{array}$ & $P \dagger$ \\
\hline No. $(\%)$ & $36(20.8)$ & $25(8.8)$ & $<.001$ \\
\hline Gender, \% F & 72.0 & 75.0 & .79 \\
\hline Language, \% Spanish & 66.7 & 32.0 & $<.01$ \\
\hline Age, $y($ mean $\pm S D)$ & $78.75 \pm 8.14$ & $80.16 \pm 9.42$ & .54 \\
\hline $\begin{array}{l}\text { Duration to dementia, y } \\
(\text { mean } \pm \text { SD })\end{array}$ & $1.79 \pm 1.02$ & $1.88 \pm 0.65$ & .67 \\
\hline $\begin{array}{l}\text { Total HRSD score } \\
(\text { mean } \pm \text { SD })\end{array}$ & $9.0 \pm 6.1$ & $2.4 \pm 2.3$ & $<.001$ \\
\hline BMIC (mean \pm SD) & $7.72 \pm 4.71$ & $7.72 \pm 5.9$ & .99 \\
\hline $\mathrm{BFAS}($ mean $\pm S D)$ & $2.89 \pm 2.8$ & $1.74 \pm 1.69$ & .05 \\
\hline
\end{tabular}

*HASD indicates Hamilton Rating Scale for Depression; BMIC, Blessed Memory Information and Concentration Test; and BFAS, Blessed Functional Activity Scale (parts 1 and 2).

$\dagger A$ test of significance for $\chi^{2}$ (categorical variables) or two-tailed test (continuous variables), as appropriate.

reaching dementia in subjects with and without depression at baseline. The Cox proportional hazards model was then recalculated with age, gender, education, language, and BMIC and BFAS scores included as covariates. Baseline depressed mood remained significantly associated with the end-point diagnosis of dementia (RR, $2.05 ; 95 \% \mathrm{CI}, 1.16$ to $3.62 ; \mathrm{P}<.02)$. The covariates of age (RR, 1.11 per year interval; $95 \% \mathrm{CI}, 1.07$ to $1.15 ; \mathrm{P}<.001$ ), education ( $R R, 1.97 ; 95 \% \mathrm{CI}, 1.05$ to $3.68 ; \mathrm{P}<.05$ ), BMIC scores (RR, 1.14 per point interval; $95 \%$ CI, 1.08 to 1.20 ; $P<.001$ ), and BFAS scores (RR, 1.14 per point interval; $95 \% \mathrm{CI}, 1.02$ to $1.28 ; P<.02$ ) were significantly associated with an increased risk of developing dementia on follow-up; gender and language showed no significant effects. Similar results were obtained when the four non-AD cases were excluded, with depressed mood significantly associated with the diagnosis of $A D$ on follow-up (RR, $1.91 ; 95 \% \mathrm{CI}, 1.07$ to $3.42 ; P=.03$ ), and the covariates of age, education, BMIC scores, and BFAS scores showed significant effects.

With the use of the same covariates, the Cox analyses were repeated with the total HRSD score as the depression variable. The results were unchanged, with the total HRSD score significantly associated with the endpoint diagnosis of dementia (RR, 1.07 per point interval; $95 \% \mathrm{CI}, 1.02$ to $1.11 ; P<.01$ ), and the covariates of age, education, BMIC scores, and BFAS scores showed significant effects. Similar results were obtained with the HRSD score dichotomized into high $(\geq 10)$ or low $(<10)$ scores (RR, $2.16 ; 95 \% \mathrm{CI}, 1.14$ to $4.08 ; P<.02)$, and the same covariates remained significantly associated with an increased risk of developing dementia on follow-up.

Of the 48 nondemented subjects with moderate cognitive impairment at baseline evaluation, $30(62 \%)$ met criteria for dementia on follow-up. One possibility is that nearly all these subjects with moderate cognitive impairment would have met criteria for dementia if followed up long enough. To control for the possibility that the definition of moderate cognitive impairment in this study was synonymous with very early dementia, the Cox proportional hazards model was recalculated after exclusion of these 48 subjects with moderate cognitive impairment. The results were unchanged, with the exception that BFAS scores no longer showed a significant effect. Baseline depression (RR, 2.31; 95\% CI, 1.04 to 5.15; $P=.04$ ), age (RR, 1.07 per year interval; $95 \% \mathrm{Cl}, 1.07$ to $1.19 ; P<.001$ ), education (RR, $3.85 ; 95 \% \mathrm{CI}, 1.62$ to 9.13 ; $P<.05$ ), and BMIC scores (RR, 1.13 per point interval; $95 \% \mathrm{CI}, 1.04$ to $1.22 ; P<.01$ ) were significantly associated with an increased risk of developing dementia on follow-up; gender, language, and BFAS scores showed no significant effects.

In the subset of 121 subjects who were assessed for the apolipoprotein E genotype, a Cox proportional hazards model evaluated the effect of age, baseline depressed mood, and the presence of the apolipoprotein $E-\epsilon 4$ 


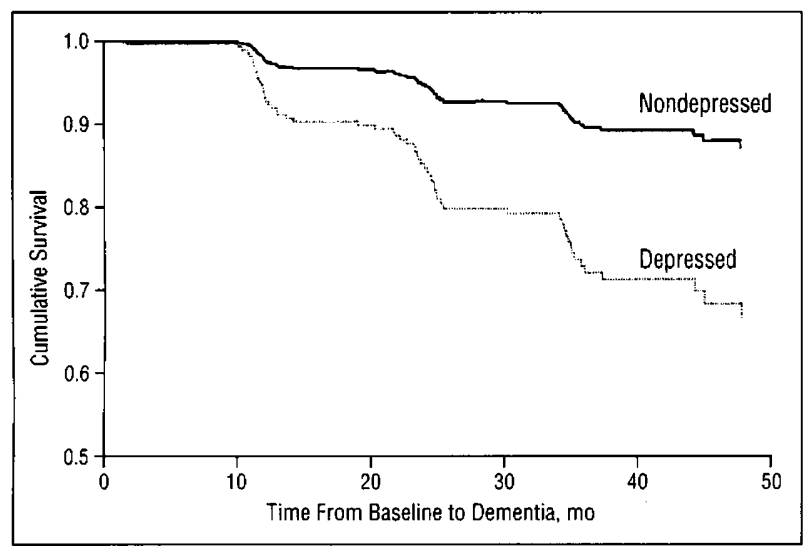

Cumulative survival for subjects with depressed mood at baseline evaluation (dotted line) and for subjects without depressed mood at baseline evaluation (solid line), as a function of time from baseline evaluation to the diagnosis of dementia during follow-up.

allele on the end-point diagnosis of dementia. In this analysis, the magnitude of the RR for reaching this end point was unchanged in subjects with depressed mood at baseline (RR, $2.82 ; 95 \% \mathrm{CI}, 0.93$ to $8.6 ; P=.07$ ). The 33 subjects with the apolipoprotein E- $\epsilon 4$ allele manifested a significantly higher relative risk for incident dementia than the 88 subjects without the apolipoprotein $E-\epsilon 4$ allele (RR, $4.79 ; 95 \% \mathrm{CI}, 1.25$ to $18.32 ; P=.02)$, and age showed a significant effect $(\mathrm{RR}, 1.12$ per year interval; $95 \% \mathrm{CI}, 1.05$ to $1.20 ; P<.001)$.

\section{COMMENT}

In community-residing elderly subjects without dementia, the presence of depressed mood was associated with a moderately increased risk of dementia on follow-up. This increased risk applied primarily to the development of $\mathrm{AD}$, because at baseline evaluation ( $89 \%)$ and during follow-up (93\%) most subjects with dementia met National Institute of Neurological and Communicative Disorders and Stroke-Alzheimer's Disease and Related Disorders Association criteria for possible or probable AD. The presence of depressed mood conferred a RR of 2.05 after controlling for all the major clinical risk factors for dementia that were evaluated, and remained significant after the non-AD dementia cases were excluded. These results were confirmed when similar results were obtained with the HRSD total score as the depression variable. In addition, in the subset in which the apolipoprotein $\mathrm{E}$ genotype was assessed, factoring in the effect of the apolipoprotein E- $\epsilon 4$ allele did not attenuate the strength of the association between depressed mood and incident dementia. Overall, the RR obtained in this prospective, longitudinal study is at the upper end of the range of the RRs observed in other epidemiologic studies that used case-control designs. ${ }^{24}$

In this study, the subjects were identified and recruited specifically for a community registry that examined risk factors for dementia, and were not randomly sampled from the general elderly population. As a result, the proportion of subjects with dementia, and of subjects with cognitive impairment but without dementia, was high. At the baseline examination of subjects with- out dementia, the prevalence of depressed mood was higher in subjects with greater cognitive impairment, as has been observed by others. ${ }^{31}$ This finding suggests that depressed mood may be more a prodromal or early sign than a risk factor for dementia. ${ }^{26,29,44}$ However, in the longitudinal data set, when the Cox analyses were conducted after removal of the subgroup with moderate cognitive impairment at baseline evaluation, depressed mood remained a risk factor for dementia. This argues against the notion that depressed mood is more a prodromal or early sign than a risk factor for dementia. Careful prospective assessment of the onset of depression and of cognitive decline would be necessary to address this issue in future research.

Another possibility is that depression-induced cognitive dysfunction led subjects to meet criteria for dementia at an earlier time point without affecting the total incidence. Several features of our study suggest that this was unlikely. Depressive symptoms were predominantly very mild to mild and therefore were unlikely to result in cognitive impairment of a magnitude sufficient to lead to the diagnosis of dementia. Of note, the cutoff scores on the neuropsychological test paradigm for the diagnosis of dementia were established after the cognitive effects of depression were taken into account and were conservative enough to avoid misclassification. Incident dementia was diagnosed only when there was measurable deterioration in cognitive performance and functional ability compared with baseline evaluation. Therefore, it is unlikely that subjects had "depressive pseudodementia" at baseline evaluation and later worsened to meet criteria for dementia during follow-up. ${ }^{1,19}$

Other epidemiologic data, obtained primarily from cross-sectional studies, have suggested a weak association between depression and cognitive impairment. In North Carolina, $2 \%$ of a community sample had a depressive disorder and some cognitive impairment. ${ }^{45}$ In the United Kingdom-United States cross-national diagnostic project, Gurland et $\mathrm{a}^{44}$ reported no association between depressive and cognitive symptoms in New York $(r=.14)$ and in London $(r=-.01)$. In an Australian community study, ${ }^{46}$ eight of 274 met diagnostic criteria for depression and dementia, a finding no different from that expected by chance. However, there was a significant association between depressive and cognitive symptoms $(r=30)$. A recent study ${ }^{31}$ from Sweden found a complex relationship between mood disturbance and cognitive impairment in 1304 community-residing subjects who were aged 75 years or older. Depressive symptoms increased as cognitive function declined, but a further cognitive decline was associated with a decrease in depressive symptoms.

Some of these discrepancies in the epidemiologic literature may result from sample size and selection and methods of ascertainment. In this study, the strengths included the large sample size, the prospective design with systematic follow-up, the direct evaluation of communityresiding subjects by physicians, detailed neuropsychological assessment to evaluate cognitive impairment and dementia, and the use of trained research personnel to assess depressive symptoms with a standard rating instrument. The use of these methods might have in- 
creased the sensitivity to detect the associations observed, in contrast to previous studies that used crosssectional designs and screening instruments to assess cognitive status.

Most of the depressed subjects had mild symptoms, a finding consistent with other epidemiologic data in the elderly.$^{24,47}$ In these mildly depressed subjects, there was an increased RR for incident dementia. One limitation was that diagnostic subtype classification of the depressive illness, eg, major depression, dysthymic disorder, or minor depression, was not attempted. It remains unclear whether the 17-item HRSD is optimal to assess depression in these subjects, and other instruments also need to be evaluated in future research. ${ }^{48,49}$ Another limitation, inherent to all community studies of this type, is that the most severely depressed subjects may have refused study participation. There was indirect evidence that this did not occur, because at baseline evaluation there was no difference in the severity of depression between those subjects who subsequently did and did not participate in the follow-up phase. The follow-up rate was less than ideal but was fairly good for a community study with large minority representation.

Although exposure to minor tranquilizers and antidepressants might be expected to be associated with cognitive impairment and an increased likelihood of a diagnosis of dementia, the few case-control studies that have examined this issue failed to find any association. ${ }^{26,27,32}$ In this study, the low frequency of antidepressant use limited statistical power and precluded any definitive conclusions.

The common occurrence of depression early during the course of intellectual deterioration has been postulated to be secondary to awareness of eroding cognitive capacities. ${ }^{7}$ Depressed patients with $\mathrm{AD}$ have degenerative changes in the noradrenergic nucleus locus ceruleus and the substantia nigra,$^{50}$ and this points to catecholaminergic deficit as a possible mechanism for the depression observed in some patients with AD. In addition, there is evidence of degeneration of serotoninergic neurons early in the course of $\mathrm{AD} .^{51}$ The onset of these early degenerative changes may be associated with depression being a prodromal or early sign in a subgroup of patients with $A D$. Other recent evidence indicates that elderly patients with major depression, particularly those with late onset, have elevated rates of baseline white matter lesions and other structural abnormalities on magnetic resonance images. ${ }^{52-55}$ However, whether this subgroup of depressed patients with subcortical lesions has an increased risk of developing dementia remains to be established. In our study, patients with historical or clinical or radiologic evidence of stroke were excluded. However, computed tomographic scans and magnetic resonance images were not available in most of these community-residing subjects, and the contribution of cerebrovascular disease to the clinical picture could not be ascertained.

In conclusion, using a prospective, longitudinal design with detailed clinical assessment in a large sample and controlling for a range of known risk factors, we found depressed mood to be associated with a moderately increased risk of dementia, predominantly AD. Depres- sion is known to worsen the prognosis in other illnesses in the elderly, eg, stroke ${ }^{56}$ and myocardial infarction. ${ }^{57}$ However, it remains unclear whether successful treatment of depression delays the time point at which the individual at risk meets clinical diagnostic criteria for AD. Another unresolved question is whether depression is a prodromal sign of AD or represents an intermediary factor related in some way to another risk factor that has yet to be identified. These issues need clarification in future research.

Accepted for publication July 28, 1995.

This work was supported by federal grants AG07232, AG08702, and AG10963 from the National Institute of Aging; MH44176 and MH50038 from the National Institute of Mental Health; and the Charles S. Robertson Memorial Gift for Research in Alzheimer's Disease.

Reprint requests to Sergievsky Center, $630 \mathrm{~W} 168$ th St, New York, NY 10032 (Dr Mayeux).

\section{REFERENCES}

1. Devanand DP, Nelson JC. Concurrent depression and dementia: implications for diagnosis and treatment. J Clin Psychiatry. 1985;46:389-392.

2. O'Connor DW, Pollitt PA, Roth M. Coexisting depression and dementia in a community survey of the elderly. Int Psychogeriatr. 1990;2:45-53.

3. Emery VO, Oxman TE. Update on the dementia spectrum of depression. Am J Psychiatry. 1992;149:305-317.

4. Roth M. The natural history of mental disorder in old age. $J$ Ment Sci. 1955; 101:281-301.

5. Kral VA. The relationship between senile dementia (Alzheimer type) and depression. Can J Psychiatry. 1983:28:304-306.

6. La Rue A, Spar J, Hill CD. Cognitive impairment in late-life depression: clinical correlates and treatment implications. J Affective Disord. 1986;11:179-184.

7. Reifler BV, Larson E, Hanley R. Coexistence of cognitive impairment and depression in geriatric outpatients. Am J Psychiatry. 1982;139:623-626.

8. Greenwald BS, Kramer-Ginsberg E, Marin DB, Laitman LB, Hermann CK, Mohs $\mathrm{RC}$, Davis KL. Dementia with coexistent major depression. Am J Psychiatry. 1989;146:1472-1478.

9. Wragg RE, Jeste DV. Overview of depression and psychosis in Alzheimer's disease. Am J Psychiatry. 1989;146:577-587.

10. Rovner BW, Broadhead J, Spencer M, Carson K, Folstein MF. Depression and Alzheimer's disease. Am J Psychiatry. 1989;146:350-353.

11. Burke WJ, Rubin EH, Morris JC. Symptoms of 'depression' in dementia of the Alzheimer type. Aizheimer Dis Assoc Disord J. 1988;2:356-362.

12. Cummings $\mathrm{JL}$. Dementia and depression: an evolving enigma. J Neuropsychiatry. 1989;1:236-242.

13. Forsell $Y$, Jorm AF, Fratiglioni $L$, Grut $M$, Winblad B. Application of $D S M-/ / 1-A$ criteria for major depressive episode to eiderly subjects with and without dementia. Am J Psychiatry. 1993;150:1199-1202.

14. Alexopoulos GS. Heterogeneity and comorbidity in dementia-depression syndromes. Int $J$ Geriatr Psychiatry. 1991;6:125-127.

15. Sackeim HA, Steif BL. The neuropsychology of depression and mania. In: Georgotas AC, Cancro R, eds. Depression and Mania. New York, NY: Elsevier Science Publishing Co Inc; 1988:265-289.

16. Reynolds CF, Kupfer DJ, Hoch CC, Stack JA, Houck PR, Sewitch DE. Two year follow-up of elderly patients with mixed depression and dementia: clinical and electroencephalographic findings. J Am Geriatr Soc. 1986;34:793-799.

17. Stoudemire A, Hill CD, Morris R, Lewison BJ. Long-term outcome of treatment resistant depression in older adults. Am J Psychiatry. 1993;150:15391540 .

18. Reding $M$, Haycox J, Blass J. Depression in patients referred to a dementia clinic. Arch Neurol. 1985;42:894-896

19. Alexopoulos GS, Meyers BS, Young RC, Mattis S, Kakuma T. The course of geriatric depression with 'reversible dementia': a controlled study. Am J PSychiatry. 1993;150:1693-1699.

20. Rabins PV, Merchant A, Nestadt G. Criteria for diagnosing reversible dementia caused by depression: validation by 2 -year follow-up. Br J Psychiatry. 1984; 144:488-492.

21. Pearlson GD, Rabins PV, Kim WS, Speedic LJ, Moberg PJ, Burns A, Bascom 
MJ. Structural brain CT changes and cognitive deficits in elderly depressives with and without reversible dementia ('pseudodementia'). Psychol Med. 1989; 19:573-584.

22. Murphy E. The prognosis of depression in old age. Br J Psychiatry. 1983;142: 111-119.

23. Baldwin RC, Jolley DJ. The prognosis of depression in old age. Br J Psychiatry. 1986;149:574-583

24. Jorm $A F$, Van Duijn $C M$, Chandra V, Fratiglioni $L$, Graves $A B$, Heyman $A$, Kokmen E, Kondo K, Mortimer JA, Rocca WA, Shalat SL, Soininen H, Hofman $A$, for the EURODEM Risk Factors Research Group. Psychiatric history and related exposures as risk factors for Alzheimer's disease: a collaborative re-analysis of case-control studies. Int J Epidemiol. 1991;20:\$43-\$47.

25. Barciay LL, Zemcov A, Blass JP, McDowell FH. Factors associated with duration of survival in Alzheimer's disease. Biol Psychiatry. 1985;20:86-93

26. Broe GA, Henderson AS, Creasey $H$, McCusker $E$, Korten AE, Jorm AF, Longley W, Anthony JC. A case-control study of Alzheimer's disease in Australia Neurology. 1990;40:1698-1707.

27. French LR, Schuman LM, Mortimer JA, Hutton JT, Boatman RA, Christians B. A case-control study of dementia of the Alzheimer type. Am J Epidemiol. 1985; 121:414-421.

28. Shalat SL, Seltzer B, Pidcock C, Baker EL. Risk factors for Alzheimer's disease: a case-control study. Neurology. 1987;37:1630-1633

29. Heyman A, Wilkinson WE, Stafford JA, Helms MJ, Sigmon AH, Weinberg $T$ Alzheimer's disease: a study of epidemiological aspects. Ann Neurol. 1984 15:335-341.

30. Kokmen E, Beard CM, Chandra V, Offord KP, Schoenberg BS. Clinical risk fac tors for Alzheimer's disease: a population based case-control study. Neurology. 1991;41:1393-1397

31. Forsell $Y$, Jorm AF, Winblad $B$. Association of age, sex, cognitive dysfunction, and disability with major depressive symptoms in an elderly sample. $A m \mathrm{~J}$ Psychiatry. 1994:151:1600-1604.

32. Soininen $\mathrm{H}$, Heinonen $\mathrm{OP}$. Clinical and etiological aspects of senile dementia. Eur Neurol. 1982;21:401-410.

33. Van Djuin CM, Stijnen T, Hofman A. Risk factors for Alzheimer's disease: overview of the EURODEM collaborative re-analysis of case-control studies. Int $J$ Epidemiol. 1991;20:S4-S11.

34. Stern Y, Andrews H, Pittman J, Sano M, Tatemichi TK, Lantigua R, Mayeux R. Diagnosis of dementia in a heterogeneous population: development of a neuropsychological paradigm-based diagnosis of dementia and quantified correction for the effects of education. Arch Neurol. 1992;49:453-460.

35. Stern $Y$, Gurland B, Tatemichi TK, Tang $M-X$, Wilder D, Mayeux R. Influence of education and occupation on the incidence of Alzheimer's disease. JAMA. 1994 271:1004-1010.

36. Blessed G, Tomlinson BE, Roth $M$. The association between quantitative measures of dementia and of senile change in the cerebral grey matter of elderly subjects. Br J Psychiatry. 1968;114:797-811

37. Hughes CP, Berg L, Danzinger WL, Coben LA, Martin RL. A new clinical scale for the staging of dementia. Br J Psychiatry. 1982;140:566-572.

38. American Psychiatric Association, Committee on Nomenclature and Statistics Diagnostic and Statistical Manual of Mental Disorders, Revised Third Edition. Washington, DC: American Psychiatric Press Inc; 1987.

39. McKhann G, Drachman D, Folstein M. Clinical diagnosis of Alzheimer's dis- ease: report of the NINCDS-ADRDA Work Group under the auspices of Department of Health and Human Services Task Force on Alzheimer's Disease. Neurology. 1984;34:939-944

40. Williams J. A structured interview guide for the Hamilton Depression Scale. Arch Gen Psychiatry. 1988;45:742-747.

41. Saunders AM, Strittmatter WJ, Schmechel D, St Goerge-Hyslop PH, PericakVance MA, Joo SH, Roses AD. Association of apolipoprotein E allele e4 with late-onset familial and sporadic Alzheimer's disease. Neurology. 1993;43:14671472.

42. Mayeux R, Stern $Y$, Ottman $R$, Tatemichi TK, Tang $M-X$, Maestre G, Ngai C, Tycko B, Ginsberg H. The apolipoprotein e4 allele in patients with Alzheimer's disease. Ann Neurol. 1993;34:752-754.

43. Lawless JF. Statistical Model and Methods for Lifetime Data. New York, NY: John Wiley \& Sons Inc; 1982.

44. Gurland B, Copeland J, Kuriansky J, Kelleher M, Sharpe L, Dean L. The Mind and Mood of Aging. London, England: Croom Helm; 1983.

45. Blazer D, Williams CD. Epidemiology of dysphoria and depression in an elderly population. Am J Psychiatry. 1980;137:439-444.

46. Kay DWK, Henderson AS, Scott R, Wilson J, Rickwood D, Grayson DA. Dementia and depression among the elderly living in the Hobart community: the effect of the diagnostic criteria on the prevalence rates. Psychol Med. 1985; 15:771-788.

47. Blazer D, Swartz M, Woodbury M, Manton K, Hughes D, George LK. Depressive symptoms and depressive diagnoses in a community population. Arch Gen Psychiatry. 1988;45:1078-1084.

48. Yesavage JA, Brink TL, Rose TL, Adey M. The Geriatric Depression Rating Scale: comparison with other self-report and psychiatric rating scales. In: Crook T, Ferris S, Bartus R, eds. Assessment in Geriatric Psychopharmacology. New Canaan, Conn: Mark Powley; 1983:153-167.

49. Alexopoulos GS, Abrams RC, Young RC, Shamoian CA. Cornell Scale for Depression in Dementia. Biol Psychiatry. 1988;23:271-284.

50. Zubenko GS, Moossy J. Major depression in primary dementia: clinical and neuropathological correlates. Arch Neurol. 1988;45:1182-1186.

51. Nordberg A. Neuroreceptor changes in Alzheimer disease. Cerebrovasc Brain Metab Rev. 1992;4:303-328.

52. Coffey CE, Figiel GS, Djang WT, Weiner RD. Subcortical hyperintensity on magnetic resonance imaging: a comparison of normal and depressed elderly subjects. Am J Psychiatry. 1990;147:187-189.

53. Baldwin RC, Benbow SM, Marriott A, Tomensen B. Depression in old age: a reconsideration of cerebral disease in relation to outcome. $B r J$ Psychiatry. 1993;163:82-90.

54. Lesser IM, Miller BL, Boone KB, Hill-Guttierez E, Mehringer CM, Wang K, Mena I. Brain injury and cognitive function in late-onset psychotic depression. $J$ Neuropsychiatry Clin Neurosci. 1991;3:33-40.

55. Krishinan KR, McDonald WM, Escałona PR, Doraiswamy PM, Na C, Figiel GS, Ellinwood EH Jr. Neuroanatomical substrates of depression in the elderly. Eur Arch Psychiatry Clin Neurosci. 1993:243:41-46.

56. Morris PLP, Robinson RG, Andrzejewski P, Samuels J, Price TR. Association of depression with 10-year poststroke mortality. Am J Psychiatry. 1993:150: 124-129.

57. Frasure-Smith $N$, Lesperance $F$, Talajic $M$. Depression following myocardial infarction: impact on 6-month survival. JAMA. 1993;270:1819-1825. 